First published in Kamposiori, C., Warwick, C. \& Mahony, S. (2017). Building Personal Collections in Art History. In: Benardou, A., Champion, E., Dallas, C., \& Hughes, L. (Eds.), Cultural Heritage Digital Tools and Infrastructure. UK: Routledge, 82-96. Publisher's website

\title{
Building Personal Research Collections in Art History
}

Christina Kamposiori, UCL Centre for Digital Humanities

Claire Warwick, Department of English Studies, University of Durham

Simon Mahony, UCL Centre for Digital Humanities

\section{Introduction}

Over the past decades, the increase in the use of digital resources and the growth of research conducted in digital environments has transformed academic scholarship. Never before was there such breadth of information and services available for scholars to use; most importantly, though, such developments offer the advantage of not only speeding up the research process, but also for facilitating innovative research inquiry. Yet, especially in the area of the Arts \& Humanities, the capabilities developed by new technologies have had a great impact on the scholarly practices of its disciplines.

In fact, these capabilities have affected the way scholars approach, create and manage information; the personal research collections of information that scholars build in the context of their research and teaching projects constitute great examples that illustrate how these practices evolve over time, the challenges that scholars meet and the particular needs that they have. In this chapter, we focus on the way that art historians build their personal information collections as a means to identify and understand the specific behaviour and requirements they have in terms of tools and services in the digital age. This will involve examining the way they gather, use and manage information in the context of their research and teaching projects.

Most of the previous studies examining the practices of scholars in the field have focused on their information seeking behaviour (Stam, 1997; Rose, 2002; Larkin, 2010; Beaudoin and Brady, 2011). Actually, this can be easily justified if we consider the importance that the initial stages of research have for the whole research process; for example, the seeking and discovery of accurate information plays a key role in producing 
reliable and credible results. However, there is not much information on what art historians do after they find the material they need for their research (Palmer, Teffeau and Pirmann, 2009). Thus, there are several questions that can be asked regarding information use and management in art history, some of which we will attempt to address in this chapter. Why do scholars choose particular resources over others for gathering the material they need? How do scholars use and manage the information they collect and what tools do they employ for these purposes? What are the challenges faced and which are the key characteristics of art historians' work when interacting with information? Managing to answer the above questions could foster significantly our understanding of art historical practices which, to a great extent, take place 'behind the scenes', at scholars' personal workspace. This knowledge, in turn, could be applied to the building of customised tools and services that better support research and teaching in the field.

We argue that the personal collections of information that art historians build for research and teaching purposes, being at the core of their workspace (Long and Schonfeld, 2014, pp. 23-25), are an important starting point for understanding behaviour and practices that are otherwise difficult to study, due to their private nature and the various personal criteria in which they develop. Finally, the observations and issues raised in this chapter are based on the results of research conducted in the context of the first author's PhD Thesis at the UCL Centre for Digital Humanities, under the supervision of Professor Claire Warwick and Mr Simon Mahony. Before continuing with the presentation of our research, we consider it necessary to provide a brief overview of some of the main studies conducted with the aim of understanding the behaviour and practices of scholars, as they can provide us with a context for examining the issues raised in the following sections.

\section{Scholarly Practices In The Digital Age}

The necessity to study the information behaviour and practices of researchers has been addressed by several studies. Ellis (1993) conducted one of the key studies in the area, which influenced later work in the field. Drawing on empirical and qualitative research, he examined the information behaviour of scholars across various disciplines. As a result, he found some common processes to occur which he presented then as features; these features were starting, chaining, browsing, differentiating, monitoring, extracting, verifying, and ending (Ellis, 1993, p. 482). A decade later, Meho \& Tibbo (2003), after studying a group of 
social scientists, discovered similar characteristics in the information behaviour of their participants with those that Ellis had found, but they added three more features: accessing, networking, and information managing.

Regarding the area of Arts \& Humanities, the importance of identifying the common practices and characteristics of the above disciplines has been stressed by many studies. Thus, Unsworth (2000) introduced the concept of the scholarly primitives, arguing that there is some common, basic behaviour that can be identified across disciplines, especially in the Arts \& Humanities; in particular, he listed the following primitives: discovering, annotating, comparing, referring, sampling, illustrating and representing, and used as examples various projects of that time.

In 2001, Brockman, et al. (2001) examined the way researchers in the Arts \& Humanities work in the new information environment. More specifically, they examined the behaviour of scholars during several research stages, such as searching, reading, writing and networking, and attempted to identify both the needs that characterise the Arts \& Humanities scholars as a whole, as well as the distinct needs of the separate disciplines included in the area. Their argument was that, as new technologies bring changes to the behaviour and needs of scholars, it is important for the institutions, in that case the academic libraries, to adapt to the new circumstances.

A year later, Palmer and Neumann (2002) examined the needs of interdisciplinary scholars in the Arts \& Humanities. In their paper, they highlighted the complex nature of this type of research and consequently, the additional needs that these researchers had. More specifically, two additional activities were found to occur during the process of this kind of research, exploration and translation, which complicated the research workflow. According to the authors, 'interdisciplinary exploration and translation complicate the already intensive information gathering, reading, and writing processes inherent in the humanities' (Palmer and Neumann, 2002, p. 107).

Palmer, Teffeau and Pirmann (2009), based on Unsworth's concept of scholarly primitives, studied the scholarly activities and primitives in a variety of different disciplines, including the Arts \& Humanities. In particular, they suggested five core scholarly activities, each of them including two or more primitives, and four additional cross-cutting primitives which can take place during more than one activity. The main activities were searching, collecting, reading, writing, and collaborating. The objective was to report on the research 
process of scholars in different fields, make relevant comparisons and, therefore, provide useful information on the requirements needed for building effective digital infrastructure for scholarship.

In addition, Blanke and Hedges (2013), by bringing together the results of various ehumanities projects conducted at the Centre for e-Research at King's College London, aimed to identify the common practices and needs of traditional and digital humanists, with respect to infrastructure work. Thus, they suggested five scholarly primitives: discovering, collecting, comparing, delivering, and collaborating. Finally, Benardou, Constantopoulos and Dallas (2013) reported on work conducted in the context of the European projects DARIAH and EHRI and they argued for the importance of understanding scholarly practices in order to provide research communities with appropriate tools and services. For that purpose, they suggested a user-centred qualitative approach - using semi-structured interviews and a conceptual model - which can be used for exploring the practices and methods employed by scholars amongst the various Arts \& Humanities communities.

\section{Building personal collections of information in the digital age}

For the purposes of this project, single face-to-face and Skype interviews with twenty art historians were conducted. These took place from June 2013 to October 2013 and, in terms of format, they were semi-structured, based on an interview guide, while each of them lasted approximately one hour. The interviews were recorded with the written consent of the participants and then transcribed using the Express Scribe software. Moreover, the interviewing phase included, when possible and with the interviewees' consent, observation of the interviewees' personal physical and/or digital collections. Again, when possible, gaining photographs of scholars' collections constituted a part of the observation process.

When the transcription phase was completed, and before the analysis stage, the transcripts were sent to the participants who confirmed the accuracy of their content. The analysis of the interviews was conducted using the NVivo software for qualitative research and the transcripts were coded according to a grounded theory approach. We started with axial coding, through identifying themes, categories and sub-categories in the data as well as specifying their properties. Then, selective coding was considered necessary for creating links between the different themes and categories and refining the codes until the issues 
raised during their analysis were of satisfying quality and depth and could be used to answer the study's research questions. The analysis procedure was complemented by the memos (reflective notes) that were kept during the coding process and the photographs and the notes taken during or after the observation which worked as a method for achieving triangulation, and thus, more accurate results.

Regarding the participants, at the time of the interviews, sixteen were based at UK institutions, while two scholars were based in Europe and another two outside of Europe. Eleven of the participants were female and nine of them male, whereas age was not a prime concern for this study; whenever is considered appropriate in this chapter, though, relevant comments will be made with regards to issues such as this and specific features of art historians' behaviour. Moreover, it is worth stating that their technical skills varied from advanced to basic. Also, the interviewees were at different career stages and, thus, they ranged from established academics to $\mathrm{PhD}$ students, early career researchers as well as independent scholars. Based on the recruitment criteria, participants needed to actively conduct research or teach in the broader area of art history.

We were particularly interested in creating a pool of interviewees consisting of two groups; one where scholars worked on commonly studied areas (e.g. various areas of European art, like Renaissance art) or employed traditional art historical methods (e.g. stylistic analysis, historical investigation) and another where the topics examined (e.g. nonWestern art, digital art) or the methods employed (e.g. quantitative, digital) were considered less traditional. Yet, it should be mentioned that this categorisation was based on the premise that the practices of scholars in the first group (twelve scholars in this study) had been frequently examined by previous studies in the field while the behaviour and needs of those in the latter (eight scholars in this study) had been less studied before (also see Rose, 2002, p. 37). Identifying any similarities and differences between these two different groups of scholars could provide a better insight into the needs that art historians in different areas of the field have in terms of resources, tools and services.

In the following section, we will present our results related to the information gathering and organisation habits of art historians in an attempt to highlight some of the key issues these scholars face and suggest potential lines of action for facilitating the needs that occur. Furthermore, we should mention that our chosen framework for presenting our 
observations is based on Palmer, Teffeau and Pirmann's (2009, pp. 16-19) term of the activity of collecting which has two primitives: gathering and organising.

\section{Gathering information}

Establishing personal collections is a common and much valued activity in art history that usually follows the seeking and discovery of information. In particular, our results showed that scholars' collections consisted of a wide variety of information objects. Since all of the participants kept both physical and digital personal collections, these information objects were either conventional or digital and of textual, visual, audio-visual or multimedia format. Regarding textual resources, they ranged from monographs, various types of books, journals, magazines, newspapers, and conference proceedings to dictionaries, photocopies and scans of various textual resources, correspondence, genealogical records, legal documents, bibliographic references, notes and mailing lists. On the other hand, the visual resources consisted of images found in printed, illustrated books and exhibition catalogues of museums and galleries, including photocopies and scans, other two dimensional kinds of material, such as $35 \mathrm{~mm}$ slides, and digital images of art objects, manuscripts or other types of objects. Finally, scholars' collections included CD-ROMs, videos, interview recordings, and 3D models and visualisations.

Generally, as art historians participating in this project told us, the beginning of research and the need to look for specific resources is usually driven by the topic under examination and the research questions. However, sometimes, it is an art object itself or its image found somewhere on the Web that marked the initiation of research and the path to be followed.

Personally, I tend to start with objects or images. So, an interest will often be sprung by looking at an image- often online just because it's easy to access- either in an image library or normally a museum website. And then if it's in a museum environment I'm going to see it. Actually, often, I mainly just rely on images. ... And then, I guess, I'll go to a library and try and learn more about it through books. (Participant 04)

Moreover, during these initial stages of research, scholars tended to gather as much information as they could find and would consider relevant to current and future projects 
(research or teaching) or to longstanding interests in a particular topic (also see Brockman, et al., 2001, p. 8).

As one of our participants argued:

So, in the beginning, I was capturing everything from administration documents to personal notes on important painters. I was capturing so much information that I didn't realisse it. It wasn't until I was at trip twenty that I really knew exactly what I needed. And so the first ones were blunt work, were cannon blast, and the next ones were surgical incisions of the impression that I was getting. (Participant 05)

Yet, as the excerpt above demonstrates, a change was often identified in the intensity with which this practice was conducted when scholars' understanding of the research topic developed, affecting accordingly the amount of information gathered. More specifically, when they reached that point, scholars looked for particular information that would enable them to construct their research argument rather than material that would provide them with an overview of the subject. Consequently, this issue may suggest that art historians may have different information needs at different stages of the research process which, in turn, may affect the information seeking practices and requirements they have in terms of resources and digital infrastructure to support their needs.

Continuing, an interesting aspect of the findings with regards to the places (digital or physical) that scholars visited to gather information was the reasons why they preferred certain resources over others. The most common factors included the degree to which the material that could be found at a certain resource was relevant to the research subject; convenience, which was mostly linked to issues of accessibility and availability; cost due to travel or copyright reasons; language; breadth and quality of material; and reliability of source, which was often determined by the trustworthiness of the provider (institution, publisher) or the author. Participant 10, below, provides an idea of the mixture of factors that influenced their decision when choosing particular resources.

The primary factor for me was firstly its accessibility, how easy or hard would be to get, how much it would cost, the language it was in and whether I understood that language or some of my colleagues were able to assist me with that. So, primarily, I stick to resources that are in English, but I can also have resources that are in Italian, Spanish and French. (Participant 10) 
Moreover, during the discussion around the main criteria upon which art historians in this study decided to use specific resources, it became apparent that some of the places visited (digital or physical) were more frequently mentioned. Therefore, the British Library was one of the places most scholars mentioned visiting at some point, either physically or virtually, when looking for information. The fact that sixteen out of the twenty participants were based at UK institutions at the time of the interviews may explain this finding to some extent. Yet, convenience or familiarity were not the only factors for visiting this well-known institution; despite their location (London-based, UK-based, outside of the UK), several of the participants mentioned visiting the British Library physically, when possible, and electronically for the great amount and variety of resources available, such as manuscripts, newspapers and so on. Other resources commonly used for research and teaching were the online collections of well-known museums such as the V\&A (Victoria and Albert Museum, London) and the MET Museum (Metropolitan Museum of Art, New York).

The Victoria and Albert Museum has a very good site where they actually have uploaded things like interviews with makers and designers. Their site is also an educational resource, so I use that. (Participant 19)

I get quite frustrated if the images are low quality. I'll try and find something in as high quality as possible. Not least because I'll usually be using it in a presentation. ... Now the MET museum offers very high quality images for free, for academic purposes, which is great. (Participant 04)

Furthermore, with regards to the digital collections used by scholars in the field of art history, it may be worth noting that only one of the interviewees referred to any of the large, collaborative, European online initiatives which enable the discovery of primary and secondary material. In this one example, Participant 09 referred to Europeana Regia, a resource which provides access to manuscripts from the Middle Ages and the Renaissance; however, the brief commentary that follows suggests that the design of the resource might not fit the needs some of the art historians interested in manuscripts might have.

The ways you can search are very limited and it's very rare actually to find a project that has been created with the end user in mind. (Participant 09) 
Additionally, Participant 16, while describing their experience with resources containing digitised print material, gave an example of potential problems that can be encountered when using such a collection.

I find that a lot of the stuff I look at it's pretty accessible. I mean sometimes you're very dependent upon how a digitisation has been done, so a lot of time if I'm looking at reports and engravings in a periodical via an online archive, the digitisation might be of very bad quality. They are often very dark, so you can't see engravings very well or they miss out the engraving completely and you don't know whether that's because of the book that they're working from, if the plate has been taken out of it or they just missed it. So, you have things like that which are a bit of a pain. You always have to remember that there are holes in the online record. (Participant 16)

Hence, these observations may indicate that even when material is already available digitally or freely accessible, it might still not be useful to researchers in the field. It can also be argued that a problematic experience with a particular resource may be considered by scholars as an additional obstacle in their journey to find and gather useful information for their projects; as a result, it may influence their decision as to which resources to consult and how to consult them (physically or digitally). Then, if physically is regarded as the preferable way to consult a resource, our interviews and observations revealed that art historians would probably decide to take their own photographs in order to enrich their personal collections with material that meets their own criteria.

Actually, visiting a place in person and taking photographs is considered essential in the cases where access to resources is problematic. More specifically, apart from few disciplinary areas which benefit from greater availability of digital resources (as in the case of Participant 16 who researched on 19th century British art), access is an issue that still concerns art history researchers. For instance, scholars dealing with primary material often encountered challenges in gathering the required information for their research since much of the material they were interested in was not digitised, in some cases in private collections, or even lost. Participant 05 's account illustrates the previous argument.

So, the constant battle that I'm under is whether or not it exists, whether or not it ever existed, and if it does exist, who has it and will they let me see it? (Participant 05) 
Regarding especially visual material, access problems can be related to copyright and cost as well as to issues concerning the design of online resources.

For example:

But, for example- and I probably shouldn't say this on the recorder [laughs], but I don't care if they know- I had an image that was in a French museum's [name changed] collection and they wanted to charge me 300 euros. And so, I just said no way. And I went and photocopied it by scanning a book. Because it is a Thesis, I have no qualms about that at all. (Participant 04)

So, every time I went to the actual site, I would take a lot of photos and thus, I have got a lot of photographs of it before it was restored. They've just been restoring it over the last year. ... So, I have them all in my computer and I do tend to use those. I guess if I was going into the field now I might actually think about trying to get familiar with the website, but I haven't because I know where my pictures are and I know what I've taken. The problem is you often want bits that aren't necessarily attractive pictures. ... It's a more useful archive for me [the interviewee's collection], because actually the one they've got you on the Web hasn't a great detail on it. Because it's actually very slow, when all you want is to come through the sort of things and, I mean, it's actually difficult to work out where you're going. I don't find it that easy to use. (Participant 03)

Therefore, it becomes evident that getting access to research material is only one aspect of the problem in art history. Accessing resources which are truly useful to scholars is another. For instance, Participant 03's comment, above, suggested that there are certain needs in the field regarding types of visual material which are not covered yet; a problem that could potentially be resolved through collaboration between information professionals and scholars.

Although digitisation and infrastructure projects have come a long way over the last few decades, there are still things to be done not only for enhancing access to research material, but for presenting this material in a way that it is useful and easy to find (as Participants 09's and 16's comments also indicate). Especially when it comes to accessing visual resources online, it is important for institutions, such as museums (which constitute the principal information providers in the field), to employ a more user-centred approach in terms of website design and facilities provided. Finally, given the interdisciplinary nature of art historical subjects, there may be cases where useful resources already exist but are not 
currently known to scholars (e.g. in the case of Participant 03, architectural resources might have been useful). In such circumstances, collaboration between scholars and content providers as well as better communication avenues for reaching researchers might help clarify such matters and improve the discovery and use of existing resources.

\section{Organising Information}

The building of personal collections of information in art history not only constitutes an ideal choice for dealing with various issues regarding research and teaching in the field, but also for creating collections that can be indexed and organised upon personal criteria. However, as collections grow, the need for their management emerges (also see Borgman, 2003, p. 3; Meho and Tibbo, 2003, pp. 582-583; Palmer, Teffeau and Pirmann, 2009, p. 18; Beaudoin and Brady, 2011, p. 32). In art history, especially, this can be a very challenging task due to the variety of formats and the personalised practices involved.

Based on our findings, although all of the scholars participating kept both physical and digital collections, there was a growing tendency to store and organise the collected research material digitally; the most popular reasons given were convenience and easy transfer of data. However, in some cases, this tendency was not necessarily in agreement with the scholars' preference over the digital or physical part of their collection. This was especially evident in the responses given regarding the potential sharing of resources.

For example:

I'll send electronic files to anybody who wants them. ... And other people have done that for me as well and no problem there at all. Books, it's a completely different matter for me. My books are mine, I don't lend them; I don't lend them to students, I don't lend them to colleagues. (Participant 11)

Generally speaking, personal collections were found to play an important role during research; for example, scholars would go back to the gathered resources when they needed to refresh their memory or rethink and re-evaluate the scholarly argument. However, what seemed to be common practice was re-visiting material from their collections during the writing stage.

For instance: 
I guess, when I'm writing something, I just get out a pile of books and use that in conjunction with resources on my computer. (Participant 20)

Furthermore, personal criteria determined the way personal collections, both physical and digital, were organised and managed; some examples included organising the files by project, labelling them by author or just keeping the label provided by a digital resource, such as an online library. Also, a common practice among scholars who were teaching at the time was to separate the material used in class from material used for research.

Concerning the 'toolkit' of the art historians in this study, it typically included several means for storing, filing and organising information. These ranged from more traditional means, like physical folders and filing cabinets, to digital tools and services, such as digital filing systems, note-taking software (e.g. Evernote), reference and bibliographic tools (e.g. Zotero, Endnote), Microsoft Office applications and other smartphone and tablet applications (e.g. Feedly, DoggCatcher). Dedicated tools for the management of images, like FileMaker Pro, Mac's iPhoto or Google's Picasa, were considered to be of great importance, even by the participants who did not use one at the time, since researchers had to deal with a great amount of visual information which often constituted a big challenge for them. Moreover, it is worth noting that the tools scholars tended to use mostly were those suggested either by their colleagues or their institutions (also see Warwick, et al., 2008), while they were more likely to use a tool when given at the start of their project and when receiving relevant training and support.

Yet, some scholars appeared to face difficulties that could not be easily tackled by using a particular tool, since they were not aware of one that could exactly fit their needs. According to the quotes below, the first scholar researching on non-Western art found it challenging to keep together the related visual and textual information needed for their research while the second, a digital art historian, faced problems due to the ephemeral nature of digital information. As a result, both cases illustrate the need for a better understanding of art historians' practices whose subjects do not belong to the traditionally researched areas, like Western art.

I need to find a method for saving the picture together with the transcription. It's no use for me if I can't read them both together. And the only way I've been able to do it is by using Power Point. Power Point is quite good for me. (Participant 08) 
I've migrated across several different platforms in terms of how I stored various things and then there's always a new way of working; there's always a slightly different way to keep art which is difficult. Quite simply some other things I end up copying and pasting into Word documents and adding as many links as I possibly can, that means I should be able to find that content again if it's migrated to different platform or the link breaks later on. But part of the nature of a lot of things that I've spent my time researching is that I won't be able to find them maybe in a few years' time anyway. So, that's why I'm trying to contextualise them now so there's at least some meta-narrative I guess on what was there even if it's not there later on. (Participant 17)

An aspect of the discussion surrounding the information practices of art historians in this study which is worth highlighting is the role that visual memory played in the organisation of the gathered material (also see Brilliant, 1988). Some of the scholars, in particular, argued that their organisation systems reflected the way their mind works and as a result it was easier for them to locate the information they needed. Additionally, organising information in specific ways could constitute a source of inspiration. For example, based on our observation of scholars' workspaces, one of the interviewees (Participant 12) was accustomed to printing out images related to the topic under examination and pin them on a board over their desk, while they would re-arrange them when needed. Looking at the pictures and creating themes through organising them in specific ways worked as a source of inspiration during research; yet, our interviewee could only follow this practice by using conventional material, since they were not aware of any related tools that would enable them to work in the same intuitive way.

Actually, there were several cases where scholars preferred to use conventional formats when carrying out specific tasks (e.g. for annotations) or for organising information (as described above). Yet, it is worth mentioning that, in this study, there was no strong relationship that could be identified between the preference for printed formats and the type of research conducted (traditional or non-traditional), the career level (junior or senior scholar), the background of the art historians (two of the participants with a background in the Sciences expressed their preference for printed formats while one highlighted their difficulty in dealing with technology) or age (younger scholars often had large collections of printed material or noted facing challenges with regards to the use of digital tools and services).

Regarding age, in particular, it may be useful to note that there have been studies arguing that, eventually, the employment of ICT tools will increase as a new generation of 
Arts \& Humanities scholars takes over (e.g. Wiberley and Jones 2000; Barret 2005); this assumption was based on the premise that younger scholars tended to adopt digital technologies more readily. However, more recent studies (e.g. Rowlands, et al. 2008; de Jong, Ordelman and Scagliola 2011; Warwick 2012) have highlighted that issues such as lack of technical skills or low employment of digital tools and services can still be encountered amongst PhD students and younger scholars, making it difficult to predict with certainty the future use of digital technologies in the Arts \& Humanities disciplines.

On the other hand, the flexibility that conventional formats offered for interacting with the material in creative and, often, visual ways tended to be one of the main reasons when choosing to work with paper resources. This brings to mind Rose's (2002, p. 38) finding about the preference that art historians in her study showed for paper systems since computer screens did not allow them to work in the way conventional formats did; an interesting issue considering that, to a great extent, is still true after more than ten years since Rose's study took place. Hence, as visual memory and creativity in terms of interaction with information was found to constitute a significant part of art historians work conducted 'behind the scenes', at their personal workspace, we believe that it should be taken into account when designing tools and services to facilitate research in the field. Similarly, further research should be conducted in order to identify the extent to which these qualities affect other information practices, such as information seeking, and how these can be integrated to digital infrastructure work.

Finally, scholars in this research wished especially for better ways to combine textual and visual information and for applications that would enable them to manage visual information according to their needs. Some, also, wished for a tool that would allow them to know what they already have in their collection, since it was sometimes difficult to remember all the material they had gathered over the years; such a tool would help them use the collected material effectively in their research and teaching. In fact, it is pertinent to say that these wishes are highly in agreement with the issues stressed so far, emphasising the importance of information organisation and management in conducting efficiently other core scholarly practices. Therefore, it is worth considering how information professionals could assist art historians in carrying out such practices while scholars' requirements and concerns should be taken into account when building digital resources and tools for facilitating research in the field. 


\section{Conclusion}

Our aim in this chapter was to use art historians' personal information collections as a departure point for looking at the practices that often follow the discovery of information in the field. More specifically, we argued that these practices, which are conducted 'behind the scenes', can be especially challenging to study; however, as they play a key role in the research process, they should be taken into account when building digital infrastructure and tools for research purposes. As a result, we presented our study's findings based on Palmer, Teffeau and Pirmann's (2009) term of the collecting activity with two primitives, gathering and organising.

In particular, we had the chance to stress some of the issues scholars participating in our research encountered during the gathering and organisation of information and how these practices affected or related to other scholarly activities. In fact, some of these problems seemed to be associated with larger issues, such as information access in the digital age, while others to the requirements of specific projects. Moreover, we looked at the tools that scholars employed during these practices and presented their wishes with regards to digital services that could fit their needs. Finally, based on our results, we pointed out issues that could be of interest to digital infrastructure stakeholders, such as scholars' criteria when choosing resources to use and key aspects of their information practices, like the role of memory and the creative aspect of art historians' work, that should be considered when creating digital services and research environments for enhancing digital scholarship.

To conclude, we strongly believe that the provision of tools and services that fit art historians' needs with regards to information use and management has the potential of facilitating the research process as a whole. However, we suggest that further study focusing on these practices is needed; as scholars will increasingly collect or create more information, one of the emergent issues to occur in the immediate future will be the necessity to manage and curate large amounts of digital data. Thus, only by developing a sound understanding of how these practices evolve, along with the challenges scholars face, can we effectively facilitate scholarship in the field with relevant and user-centred digital resources and services. 


\section{References}

Barrett, A., 2005. The Information-Seeking Habits of Graduate Student Researchers in the Humanities. The Journal of Academic Librarianship, 31(4), pp. 324-331.

Benardou, A., Constantopoulos, P. and Dallas, C., 2013. An Approach to Analyzing Working Practices of Research Communities in the Humanities. International Journal of Humanities and Arts Computing, 7(1/2), pp. 105-27.

Blanke, T. and Hedges, M., 2013. Scholarly primitives: Building institutional infrastructure for humanities e-Science. Future Generation Computer Systems, 29(2), pp. 654-661.

Beaudoin, J.E. and Brady, J.E., 2011. Finding Visual Information: A Study of Image Resources Used by Archaeologists, Architects, Art Historians, and Artists. Art Documentation: Journal of the Art Libraries Society of North America, 30 (2), pp. 24-36.

Borgman, C.L., 2003. Personal Digital Libraries: Creating Individual Spaces for Innovation. NSF Workshop on Post-Digital Libraries Initiative Directions. Chatham, MA, September 2005.

Brilliant, R., 1988. How an Art Historian Connects Art Objects and Information. In: Stam, D.C. \& Giral, A., eds. 1988. Linking Art Objects and Art Information. Library Trends, 37(2), pp. 120-29.

Brockman, W.S., Neumann, L., Palmer, C.L. and Tidline, T.J., 2001. Scholarly Work in the Humanities and the Evolving Information Environment'. Washington, D.C.: Digital Library Federation and Council on Library and Information Resources.

de Jong, F.M.G., Ordelman, R.J.F. and Scagliola, S., 2011. Audio-visual Collections and the User Needs of Scholars in the Humanities: a Case for Co-Development. In: Proceedings of the 2nd Conference on Supporting Digital Humanities (SDH 2011), 17-18 Nov. 2011.

Copenhagen, Denmark. Copenhagen: Centre for Language Technology.

Ellis, D., 1993. Modeling the information-seeking patterns of academic researchers: A grounded theory approach. The Library Quarterly, 63(4), pp. 469-486.

Europeana Regia. [online] Available at: <http://www.europeanaregia.eu/en $>$ [Accessed 20 August 2015].

Larkin, C., 2010. Looking to the Future While Learning from the Past: Information Seeking in the Visual Arts. Art Documentation: Journal of the Art Libraries Society of North America, 29(1), pp 49-60.

Long, M. and Schonfeld, R.C., 2014. Supporting the Changing Research Practices of Art Historians. ITHAKA S+R. [online] Available at: <http://www.sr.ithaka.org/researchpublications/supporting-changing-research-practices-art-historians $>$ [Accessed 1 May 2014]. 
Meho, L.I. and Tibbo, H.R., 2003. Modeling the Information-Seeking Behavior of Social Scientists: Ellis's Study Revisited. Journal of the American Society for Information Science and Technology, 54(6), pp. 580-587.

Palmer, C.L., Teffeau, L.C. and Pirmann, C.M., 2009. Scholarly Information Practices in the Online Environment. Themes from the Literature and Implications for Library Service Development. Dublin, Ohio: OCLC Online Computer Library Center, Inc. [online] Available at: <www.oclc.org/programs/publications/reports/2009-02.pdf $>$ [Accessed 16 January 2010].

Rose, T., 2002. Technology's Impact on the Information-Seeking Behavior of Art Historians. Art Documentation: Journal of the Art Libraries Society of North America, 21(2), pp. 35-42.

Rowlands, I., Nicholas, D., Williams, P., Huntington, P., Fieldhouse, M., Gunter, B., Withey, R., Jamali, H.R., Dobrowolski, T. and Tenopir, C., 2008. The Google generation: the information behaviour of the researcher of the future. Aslib Proceedings, 60(4), pp. 290-310.

Stam, D.C., 1997. How Art Historians Look for Information. Art Documentation: Journal of the Art Libraries Society of North America, 16(2), pp. 27-30.

Unsworth, J., 2000. Scholarly primitives: what methods do humanities researchers have in common, and how might our tools reflect this? Humanities Computing: formal methods, experimental practice. King's College London, 13 May 2000. [online] Available at: $<$ http://people.brandeis.edu/ unsworth/Kings.5-00/primitives.html $>$ [Accessed 10 January 2013].

Warwick, C., 2012. Studying users in digital humanities. In: Warwick, C., Terras, M. and Nyhan, J. (Eds.), Digital Humanities in Practice. London, UK: Facet Publishing, pp. 1-21.

Warwick, C., Terras, M., Galina, I., Huntington, P. and Pappa, N., 2008. Library and Information Resources and Users of Digital Resources in the Humanities. Program: Electronic Library and Information Systems, 42(1), pp. 5-27. [online] Available at: $<$ http://dx.doi.org/10.1108/00330330810851555> [Accessed 23 May 2012].

Wiberley, S. and Jones, W.G., 2000. Time and technology: a decade-long look at humanists' use of electronic information technology. College and Research Libraries, 61(5), pp. 421431. 